\title{
Estimating the Relevant Source Area of Pollen in the past cultural landscapes of southern Sweden - A forward modelling approach
}

\author{
Sofie Hellman a,*, Marie-José Gaillard ${ }^{\mathrm{a}, *}$, Jane Mairi Bunting ${ }^{\mathrm{b}}$, Florence Mazier ${ }^{\mathrm{a}}$ \\ a School of Pure and Applied Natural Sciences, Kalmar University, SE-391 82 Kalmar, Sweden \\ b Department of Geography, University of Hull, Cottingham Road Hull, HU6 7RX, United Kingdom
}

\section{A R T I C L E I N F O}

\section{Article history:}

Received 13 March 2008

Received in revised form 25 August 2008

Accepted 26 August 2008

Available online 13 September 2008

\section{Keywords:}

HUMPOL computer mode

past cultural landscapes

Relevant Source Area of Pollen (RSAP)

Landscape Reconstruction Algorithm (LRA)

southern Sweden

\begin{abstract}
A B S T R A C T
In this paper, we estimate the Relevant Source Area of Pollen (RSAP) in past hypothetical landscapes of the Middle and Late Holocene in southern Sweden, in order to explore the possible effects of past changes in vegetation composition, openness and structure in terms of patch size and spatial distribution. The RSAP of small basins (bogs or lakes) in the past has to be estimated if quantitative reconstruction of past vegetation at the local spatial scale is to be achieved using Sugita's Landscape Reconstruction Algorithm (LRA). In this study we apply a forward modelling approach to estimate past RSAP using the computer simulation model HUMPOL. The landscape designs are based on past landscape maps produced using a combination of palaeobotanical, archaeological and historical data, and the area's geology and soil characteristics. Four time windows characterised by different landscape/land-use were selected, i.e. Early Neolithic, Late Bronze Age, Viking Age, and Middle Ages. We found that RSAP estimates for hypothetical past landscapes in Skåne differ by ca. $600 \mathrm{~m}$ to $1200 \mathrm{~m}$ between the selected time periods, whatever the size of the basin (lake or bog, 25$250 \mathrm{~m}$ radius). The most probable explanation for the differences in RSAP between time slices is variable patch size and spatial distribution of patches in the landscape. The RSAPs vary between ca. 1200 and $2300 \mathrm{~m}$ for small basins ( $25 \mathrm{~m}$ and $70 \mathrm{~m}$ radius), and between ca. 2000 and $3000 \mathrm{~m}$ for larger basins ( $250 \mathrm{~m}$ radius). These values are within the range of earlier estimates of modern and past RSAPs for southern Scandinavia obtained using simulated or empirical data. These results suggest that, given the type of setting of that region in terms of taxa composition and traditional land-use, the RSAP for small-size lakes (25-250 m radius) will generally be in the range ca. $1200-3000 \mathrm{~m}$. The forward modelling approach is found to be useful to assess the possible effects on RSAP of changes in vegetation/landscape characteristics between different periods of the past. Moreover, comparison of RSAP estimates obtained using both the forward and backward modelling approaches will be important to identify the most credible RSAP estimates for the past.
\end{abstract}

(C) 2008 Elsevier B.V. All rights reserved.

\section{Introduction}

Defining the spatial scale of vegetation represented by fossil pollen is a critical step for objective interpretation of palynological records (e.g. Davis, 2000). Because pollen grains can potentially be carried by wind hundreds or thousands of meters (Birks and Birks, 1980), pollenbased reconstruction of the spatial distribution of plant taxa in vegetation and landscapes has been difficult. Intertaxonomic differences in pollen dispersal and production also complicate the relationship between pollen assemblages and the surrounding vegetation even when similarly-sized sites are used (Sugita, 1994). Recent theoretical work has shown that the source area of pollen is one of the necessary parameters for quantitative reconstruction of vegetation (Sugita, 2007b).

\footnotetext{
* Corresponding authors. Hellman is to be contacted at Tel.: +46 480446176; fax: +46 706080167. Gaillard, Tel.: +46 706080167.

E-mail addresses: sofie.hellman@hik.se, sofie.hellman@gmail.com (S. Hellman), marie-jose.gaillard-lemdahl@hik.se (M.-J. Gaillard).
}

Pollen source area can be defined in various ways. Since the early 1960s, several palaeoecologists have discussed the patterns and processes of pollen representation of vegetation and have proposed concepts and methodologies to tackle this problem (Davis, 1963; Tauber, 1965; Kabeiliene, 1969; Andersen, 1970; Berglund, 1973; Janssen, 1973; Jacobson and Bradshaw, 1981; Prentice, 1985, 1988). In particular, based on the pioneering works by Tauber (1965), Kabeiliene (1969) and Andersen (1970), Prentice (1985, 1988) proposed a comprehensive theoretical framework that makes it possible to relate major factors, such as basin size, pollen productivity and dispersal, to pollen accumulation on a sedimentary basin. Assuming homogenous vegetation, Prentice's model (1985) can provide the pollen source area of individual taxa or the "characteristic radius", i.e. the area (distance in meters) in the vegetation from within which a certain percentage of the pollen of a given taxon originates. For example, in the case of a bog with 100 m radius, the " $50 \%$ radius" for Quercus is $2.0 \mathrm{~km}$, which means that $50 \%$ of all pollen of this taxa deposited on the bog comes from within $2.0 \mathrm{~km}$ around the bog. In homogenous vegetation, the "characteristic radius" depends mainly 
on the size of the sedimentary basin and fall speed of pollen of a given species (Prentice, 1988). The model predicts that the larger the basin size, the larger the spatial scale of vegetation represented by pollen, which reflects the empirical observations obtained by Berglund (1973), Bradshaw and Webb (1985), and others. Prentice's model was thus useful to understand the factors and mechanisms that influence the pollen representation of vegetation. However, vegetation and landscapes are heterogeneous and patchy in general. The "characteristic radius", because it assumes homogeneous vegetation, does not provide a realistic picture of the pollen source area in regions where spatial heterogeneity of the landscape is the norm.

Sugita (1994) introduced spatial heterogeneity into the discussion of the spatial scale of vegetation represented by pollen, and proposed the concept of the "Relevant Source Area of Pollen" (RSAP). Using simulated patchy landscapes comparable to an old-growth forest in northern Michigan of the United States, Sugita demonstrated that the goodnessof-fit of the linear model of the relationship between pollen loading (number of pollen grains deposited per unit area per year) and vegetation abundance surrounding sites (Prentice, 1985; Sugita, 1993) to the observed pollen-vegetation relationship approaches an asymptote and does not improve beyond a certain distance from the deposition basin in a given region. This distance is defined as the RSAP (Sugita, 1994). Simulations have shown that pollen coming from beyond the RSAP becomes nearly constant among similarly-sized sites, and that the differences in pollen loading among sites reflect the differences in vegetation abundance within the RSAP among sites (Sugita, 1994, 1998). The RSAP can also be estimated using pollen percentages, a common measure of pollen abundance in sediments. Calcote (1995), Broström et al. (2005), Nielsen and Sugita (2005) and others have demonstrated that the RSAP can also be empirically measured in modern landscapes and that simulated estimates in the same landscapes are very similar to the empirical estimates. This implies that the simulation approach can be used to estimate past RSAP (Nielsen and Sugita, 2005).

Although several palynologists have attempted vegetation reconstruction by incorporating the "background pollen" component, their applications have been limited. For example, Andersen (1970) found that pollen coming from beyond $20-30 \mathrm{~m}$ from moss polster samples is negligible in modern Draved Forest in Denmark, and applied his model to reconstruct past vegetation in the area (Andersen, 1973). Prentice and Parsons (1983) proposed an inverse form of the Extended $R$-value (ERV) model (see below) that includes the "background pollen" component for vegetation reconstruction. Although these models were innovative in palaeoecological research, their definitions of the "background pollen" were assuming constant background through time, making reconstructions of past landscape/vegetation difficult as "background pollen" loading in small sites actually does change between landscape/ vegetation types and through time (Sugita, 1994; Sugita et al., 1999; Sugita, 2007a,b). Sugita (2007a,b) demonstrated that quantitative reconstruction of vegetation and landscape requires a strict definition of the "background pollen" component and the source area of pollen, and he proposed the Landscape Reconstruction Approach (LRA) (see below) as a theoretically sound basis for quantitative vegetation reconstruction. In that framework, the RSAP is clearly-defined and measurable, and can be used as a quantifiable parameter for the reconstruction of past vegetation and landscapes (Sugita, 2007b). However, estimating RSAP in the past is still a challenge, because the RSAP is strongly influenced by the spatial patchiness and heterogeneity of the landscape (Bunting et al., 2004; Broström et al., 2005; Nielsen and Sugita, 2005; Sugita, 2007b; Hellman et al., 2009).

The Landscape Reconstruction Algorithm (LRA) was developed by Sugita (2007a,b) for quantitative reconstruction of vegetation from pollen samples. It has been tested and applied in several studies (e.g. Hellman et al., 2008a,b; Nielsen, 2004; Sugita et al., in press). The LRA includes two models, REVEALS (Regional Estimates of VEgetation Abundance from Large Sites) and LOVE (LOcal Vegetation Estimates). Both models correct for representation biases due to pollen dispersal and deposition characteristics of individual taxa. REVEALS estimates regional vegetation abundance using pollen data from large sites (bogs or lakes). Estimates of regional vegetation are needed to estimate the background pollen component for small sites. Using pollen data from small sites, LOVE estimates local vegetation abundance within the Relevant Source Area of Pollen (RSAP sensu Sugita, 1994; see below for definition) of these small sites. Therefore, the RSAP of small basins in the past has to be estimated if quantitative reconstruction of past vegetation at the local spatial scale is to be achieved using the LRA. LOVE includes a backward modelling approach to estimate past RSAP (Sugita, 2007b). In this paper, we explore the differences and changes in RSAP in southern Sweden in the second half of the Holocene using a forward modelling approach. The aim is to provide further insights on the factors influencing the RSAP and a mean of comparison with the results obtained using the backward modelling approach. The latter will strengthen the basis for quantitative reconstruction of vegetation at the local spatial scale using the LOVE model (Sugita, 2007b).

To estimate RSAP, one needs pollen-vegetation datasets, empirical or simulated, including pollen data from a large number of sites (moss polsters, bogs or lakes) and spatial distribution of source plants obtained from real landscapes (such as satellite images or vegetation and inventory maps (e.g. Calcote, 1995; Broström et al., 2005; Mazier et al., 2008; Nielsen, 2004) or from simulated hypothetical landscapes (e.g. Sugita, 1994; Sugita et al., 1999; Bunting et al., 2004). In the case of a hypothetical landscape, pollen data (i.e. pollen loading on bogs or lakes) have to be simulated using ERV-models (Prentice, 1985) and the vegetation data extracted from the simulated landscape. Prentice's model relate pollen loading on a sedimentary basin and four major factors affecting pollen loading, i.e. pollen productivity, pollen dispersal, spatial distribution of source plants, and basin size. It provides the theoretical basis for the linear relationship between pollen loading and vegetation abundance of a given species, or the total sum of source plant abundance weighted according to distance from the sedimentary basin. Plant abundance is distance-weighted (preferably using a species-specific weighting method; see discussion in Broström et al., 2004) because individual plants close to the basin will provide more pollen grains to the basin than the same amount of plants farther away. The model implies that the slope of the linear relationship between pollen loading and distance-weighted vegetation represents the pollen productivity of the species; moreover, the linear function includes a "background pollen" term (the intercept). There are three versions of ERV-models. ERV-model 1 (Parsons and Prentice, 1981) and ERV-model 2 (Prentice and Parsons, 1983) are appropriate to describe the pollen-vegetation relationship using pollen records from bogs and mires, where horizontal movement of pollen after deposition is negligible. Because mixing and focusing redistribute the pollen originally deposited on a lake (e.g. Davis et al., 1984), Sugita (1993) modified Prentice's model to estimate pollen deposition over the entire surface of the basin (lakes and ponds) (ERVmodel 3). This model assumes that plant abundance is measured in absolute values, and that the background pollen loading is constant between sites (see Introduction section for ERV-models). The three ERV-models should give very similar results if background pollen loading is low compared to total pollen loading (Jackson and Kearsley, 1998). The basic assumptions for the Prentice's and Sugita's models are described in Sugita (1994). The pollen dispersal-deposition function used in the Prentice's and Sugita's models defines how a given abundance of plants at a certain distance is registered in pollen records. Sugita proposed two additional models for pollen dispersaldeposition on lakes and ponds that improve the accuracy of the pollen-loading calculation, i.e. the Finite Line Source model (Sugita et al., 1997) and the Ring-Source model (Sugita et al., 1999). The latter has been implemented as the kernel of pollen dispersal and deposition in the most recent simulation studies using the Prentice's and Sugita's models (Nielsen, 2004; Nielsen and Sugita, 2005; Soepboer et al., 
2007; Sugita, 2007b). In the Ring-Source model the pollen source is expressed as a succession of concentric rings around the pollen site out to the largest distance of the vegetation survey.

A major objective of this paper is to provide insights into past changes in the RSAP in southern Sweden, particularly during the periods of major human impacts including (1) Early Neolithic time (40003300 cal. yr BC), (2) Late Bronze Age (1000-500 cal. yr BC), (3) Viking Age (AD 800-1050 cal. yr), and (4) Medieval time (AD 1050-1500 cal. yr). Berglund et al. (1991) summarized the cultural landscape changes in the Ystad region, southern Sweden, during the last 6000 years. The results were also synthesized in vegetation/landscape maps based on all available data (palaeoecology, archaeology, history, geology, geography). In this study, we apply a forward modelling approach, i.e. we use the maps of past vegetation to simulate landscapes that are comparable to those in the Ystad area during the four selected periods, and evaluate the changes in RSAP between these past landscapes. To meet our objective, we apply the simulation approach using the computer model HUMPOL (Middleton and Bunting, 2004; Bunting and Middleton, 2005), a successor of Sugita's POLLSCAPE model (Sugita, 1994, 1998; Sugita et al., 1999). Both computer models include Sugita's (1993) and Prentice's

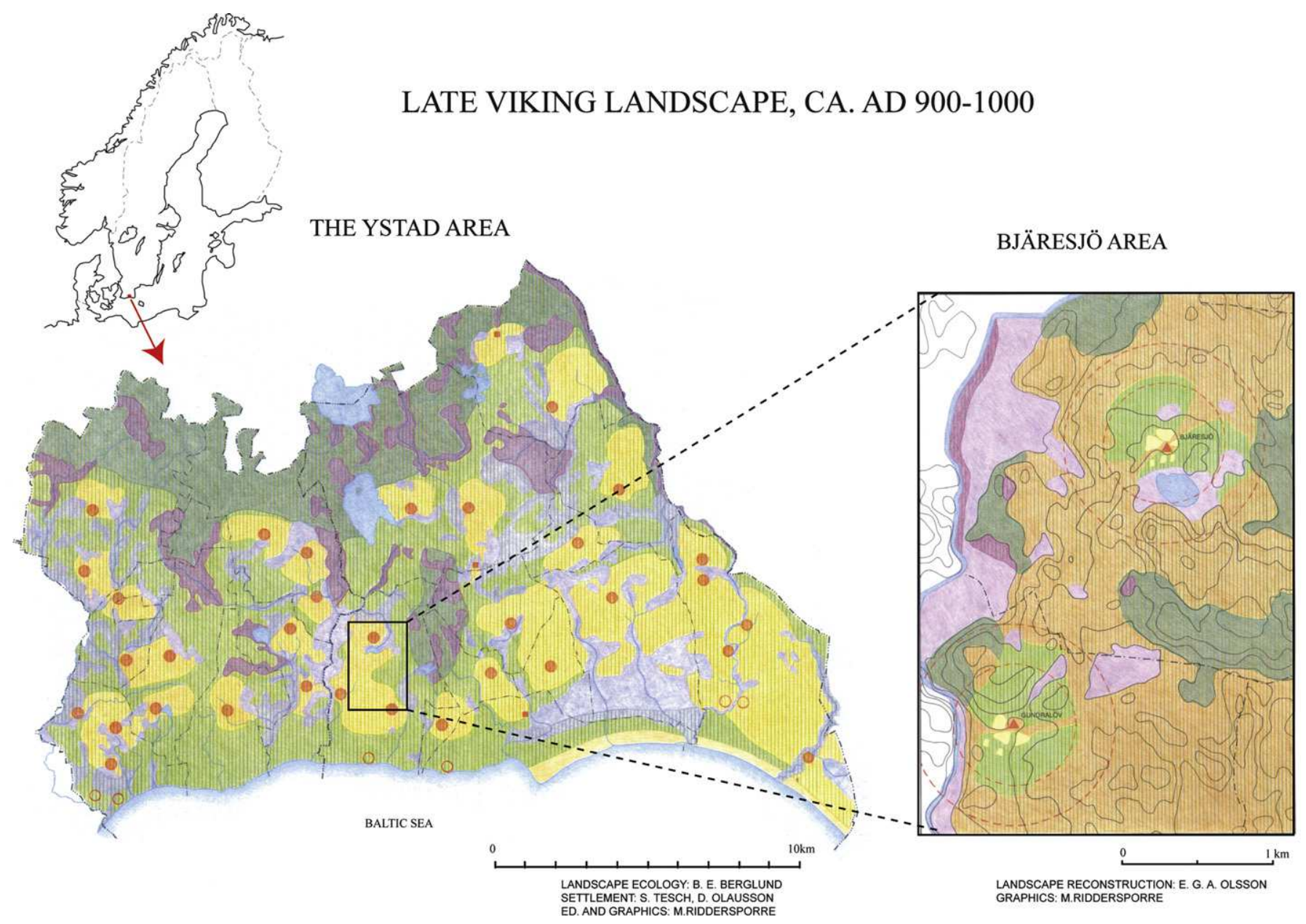

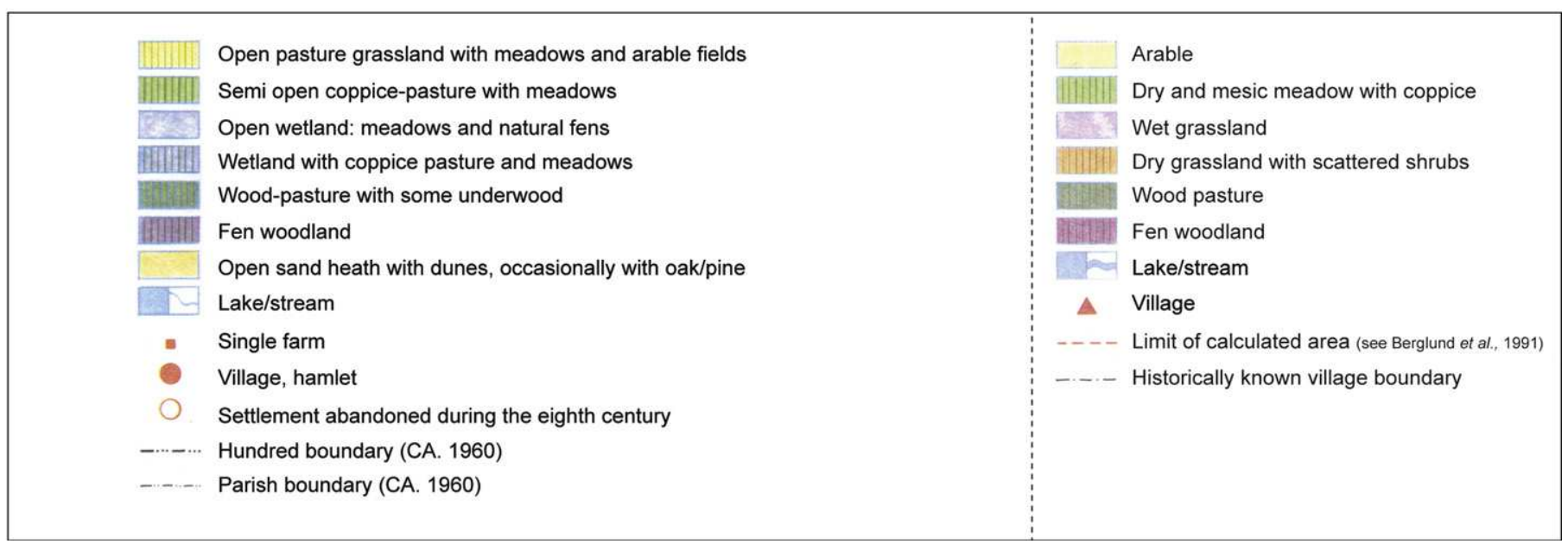

Fig. 1. Location of the Ystad project study area (southern Skåne, Sweden) in Scandinavia, and maps produced within the project for the Viking Age time slice (modified from Berglund, 1991), i.e. the regional map (Ystad "region") and the local map (Bjäresjö area). 
$(1985,1988)$ model options to express pollen dispersal and deposition, and require pollen productivity estimates (PPEs) (e.g. Sugita et al., 1999; Nielsen, 2004; Broström et al., 2005; Mazier et al., 2008). HUMPOL may be described as a user-friendly successor of POLLSCAPE with greater flexibility, applying a pixel-based rather than ring-based approach (i.e. the Ring-Source model of Sugita in Sugita et al., 1999, see above) and slightly different algorithms to extract vegetation data. POLLSCAPE has been validated by simulating pollen assemblages in modern landscapes and comparing them with modern pollen assemblages. POLLSCAPE has been shown to be effective to simulate pollen assemblages from small forest hollows (Davis, 2000) and small lakes (Sugita et al., 1997) in forests of North America, and from small lakes in the modern cultural landscapes of southern Sweden (Sugita et al., 1999) and the historical AD 1850 landscapes of Denmark (Nielsen, 2004).

\section{Methods}

\subsection{Designing past landscapes}

The maps produced within the "Ystad project" in southern Sweden are a unique example of an attempt at visualization of past landscapes for several time windows at various spatial scales, i.e. local (16 $\mathrm{km}^{2}$ and $48 \mathrm{~km}^{2}$ ) and regional $\left(625 \mathrm{~km}^{2}\right.$ ) (Berglund et al., 1991; Fig. 1). We used these maps as the basis (Fig. 2) to design simple past landscapes (Fig. 3) with the program MOSAIC v3.2 (Middleton and Bunting, 2004).

The basic parameters used to produce the "Ystad project's" maps were settlement patterns (derived from archival and archaeological sources), palaeobotanical data, maps of Quaternary geology (peat, glacial and fluvial sediments), an 1812-1820 hydrological map (assumed to show a near-natural drainage and wetland distribution) and models of palaeohydrological changes. Human activity is assumed to have varied depending on soil type. For this study, we focused on four time windows:

1. Early Neolithic time (4000-3300 BC): a mostly wooded mosaic vegetation with small patches of cultivated fields and grazing land dispersed over the landscape

2. Late Bronze Age (1000-500 BC): a mixed wooded-open landscape with large patches of cultivated fields and grazing land concentrated around farms and settlements

3. Viking Age (AD 800-1050): a mixed wooded-open landscape with large patches of cultivated fields and grazing land concentrated around farms and settlements; the landscape openness was somewhat larger than during the Late Bronze Age

\section{LATE VIKING LANDSCAPE, CA. AD 900-1000}
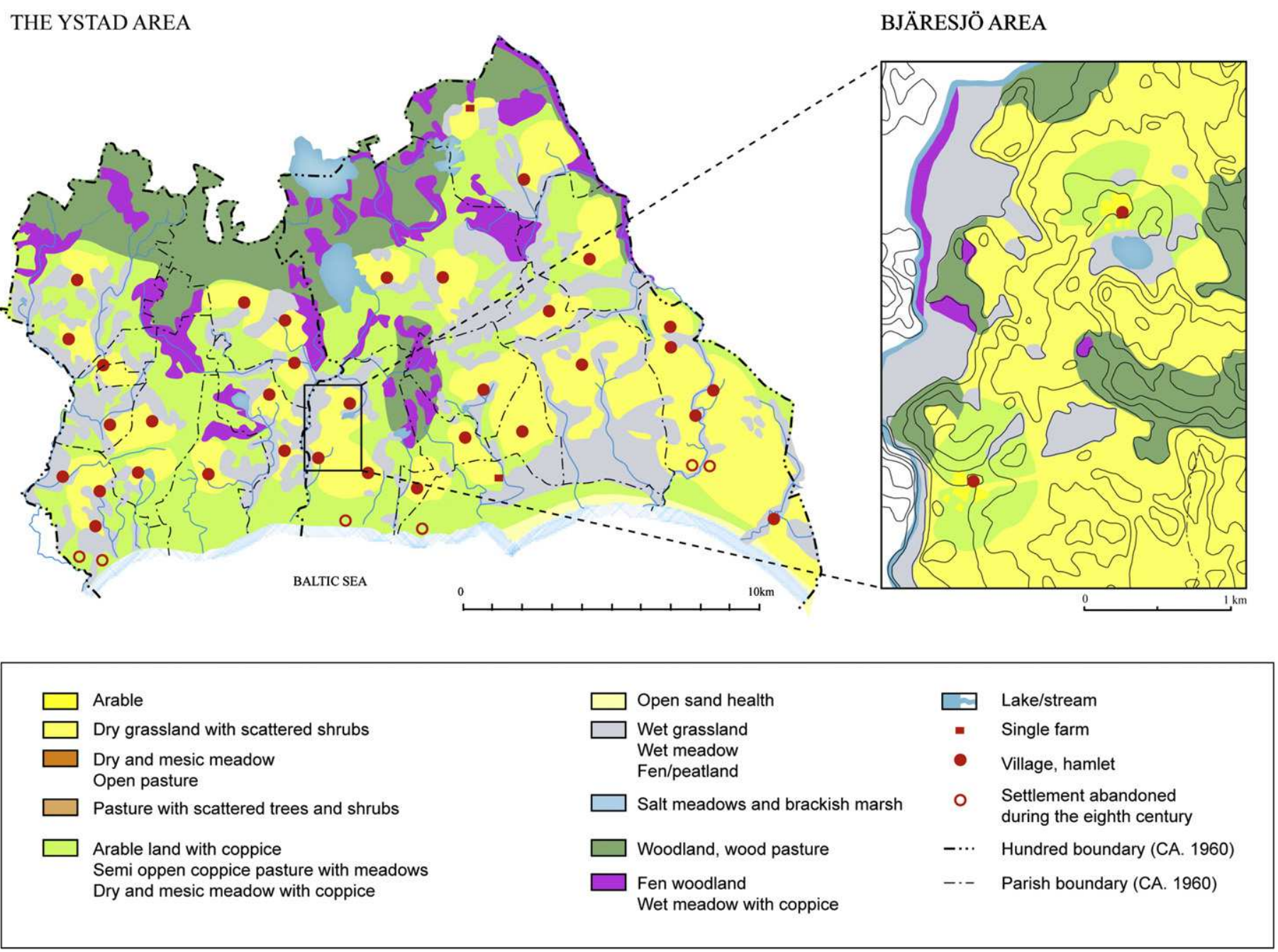

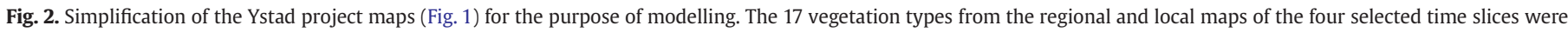
grouped into 10 different vegetation types (P1-P10) (see Table 1). 
A

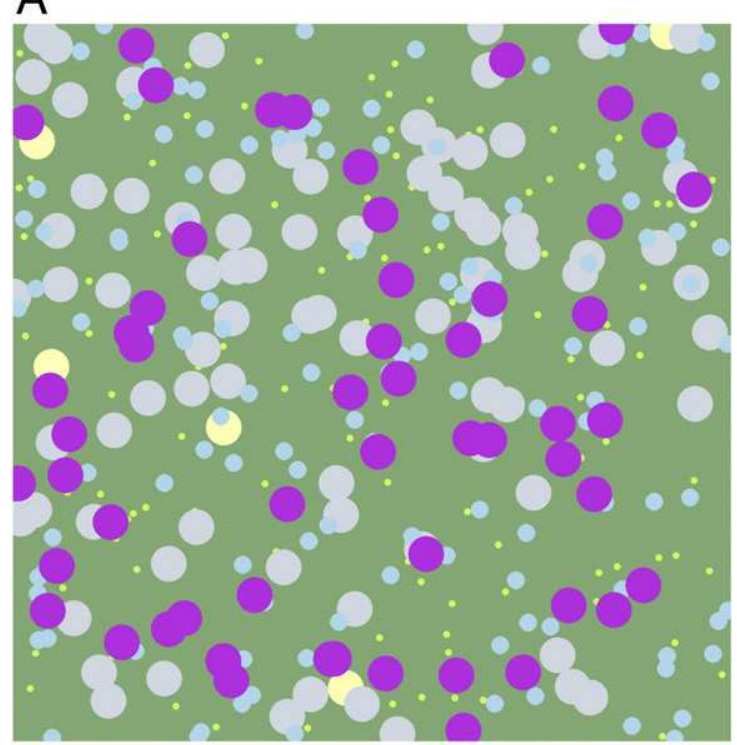

C

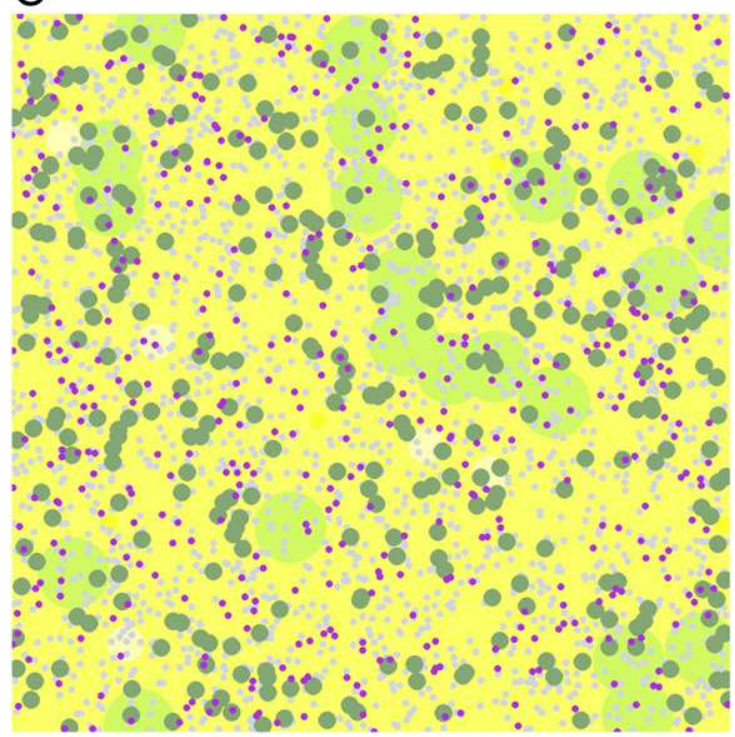

B

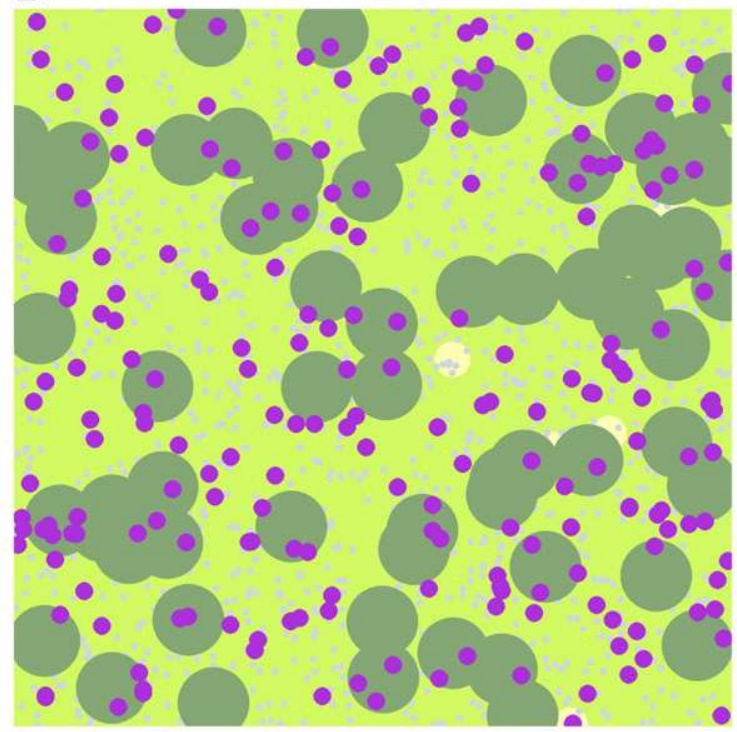

D

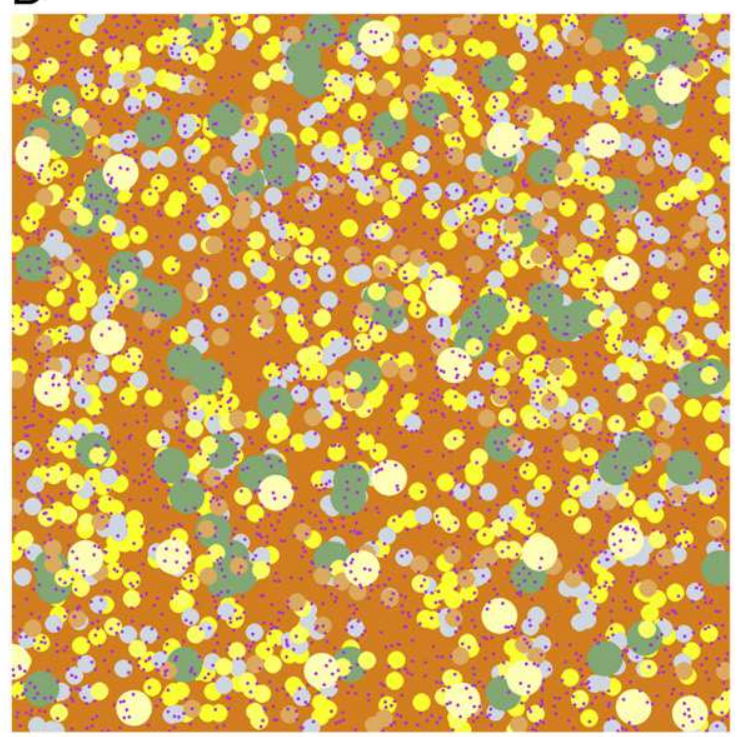

$5 \mathrm{~km}$

A Early Neolithic

B Late Bronze Age

C Viking Age

D Middle Ages

Fig. 3. Mosaic landscapes for each selected time window: A) Early Neolithic, B) Late Bronze Age, C) Viking Age, D) Middle Ages. For colour codes of vegetation types, see Fig. 2.

4. Medieval time (AD 1050-1500): an open landscape with large patches of cultivated fields and grazing land concentrated around villages; cultivated fields cover a larger area than during the Viking Age.

The vegetation types/patches and their percentage covers and patch sizes extracted from the original maps of past landscapes from Berglund (1991) are presented in Tables 1 and 2. We used the localscale maps from the Köpinge area for the Early Neolithic, and those from the Bjäresjö area for the Late Bronze Age, Viking Age, and Middle Ages (Berglund, 1991). The 17 vegetation types found on the Ystad project's maps were grouped into 10 combined vegetation types/ patches (P1-P10) (Table 1). The original maps (Fig. 1) were simplified using the modified system of vegetation types/patches applied in the simulated landscapes (Fig. 2). The sizes of the 10 patches were extracted from the redrawn map by measuring them and calculating the mean size. Because patches are not round, we measured the length and width of each patch. Moreover, in the case of very large, irregular patches, such as P7 in the Bjäresjö map of Fig. 2, the entire surface was treated as several patches of a diameter equal to the largest width of the area. Similarly, the cover of each patch was extracted from the 
Table 1

Vegetation types (1-17) in the Ystad project's maps and their corresponding types used in the simulations (P1 to P10) together with their percentage cover in the landscapes of the Early Neolithic (EN) based on the Ystad project's local map of the Köpinge area, and the Late Bronze Age (LBA), Viking Age (VA) and Middle Ages (MA) based on the local maps of the Bjäresjö area. Abbreviations: $\mathrm{MX}=$ matrix in the MOSAIC landscape design

\begin{tabular}{|c|c|c|c|c|c|}
\hline \multicolumn{2}{|c|}{ Time window } & $\begin{array}{l}\text { Early } \\
\text { Neolithic }\end{array}$ & $\begin{array}{l}\text { Late Bronze } \\
\text { Age }\end{array}$ & Viking Age & Middle Ages \\
\hline \multicolumn{2}{|c|}{ Map size } & $5 \mathrm{~km} \times 4 \mathrm{~km}$ & $2.5 \mathrm{~km} \times 3.5 \mathrm{~km}$ & $2.5 \mathrm{~km} \times 3.5 \mathrm{~km}$ & $3 \mathrm{~km} \times 3 \mathrm{~km}$ \\
\hline \multicolumn{2}{|c|}{ Vegetation types } & Cover \% & & & \\
\hline \multicolumn{6}{|c|}{$\overline{\text { Simplified Ystad maps }}$} \\
\hline P1 & 1. Arable land & & 0.2 & 0.5 & 20 \\
\hline & $\begin{array}{l}\text { 2. Dry grassland } \\
\text { with scattered } \\
\text { shrubs }\end{array}$ & & & 15 & 8 \\
\hline \multirow[t]{3}{*}{ P3 } & $\begin{array}{l}\text { 3. Dry and mesic } \\
\text { meadow }\end{array}$ & & & & MX 18 \\
\hline & 4. Open pasture & & & & 4 \\
\hline & Total P3 & & & & MX 22 \\
\hline P4 & $\begin{array}{l}\text { 5. Pasture with } \\
\text { scattered trees } \\
\text { and shrubs }\end{array}$ & & & & 7 \\
\hline \multirow[t]{3}{*}{ P5 } & $\begin{array}{l}\text { 6. Arable land } \\
\text { with coppice }\end{array}$ & 1 & & & \\
\hline & $\begin{array}{l}\text { 7. Dry grassland } \\
\text { (local map) } \\
\text { 8. Semi open } \\
\text { coppice pasture } \\
\text { with meadows } \\
\text { (regional map) }\end{array}$ & & MX 40 & & \\
\hline & $\begin{array}{l}\text { 9. Dry and mesic } \\
\text { meadow with } \\
\text { coppice }\end{array}$ & & & MX 50 & \\
\hline P6 & $\begin{array}{l}\text { 10. Open sand } \\
\text { heaths }\end{array}$ & 1 & 1 & 1 & 5 \\
\hline \multirow[t]{4}{*}{ P7 } & $\begin{array}{l}\text { 11. Wet } \\
\text { grassland }\end{array}$ & & 9.4 & 15 & \\
\hline & $\begin{array}{l}\text { 12. Wet } \\
\text { meadow }\end{array}$ & & & & 15 \\
\hline & $\begin{array}{l}\text { 13. Fen, } \\
\text { peatland }\end{array}$ & 15 & & & 5 \\
\hline & Total P7 & 15 & 9.4 & 15 & 20 \\
\hline P8 & $\begin{array}{l}\text { 14. Salt } \\
\text { meadows and } \\
\text { brackish marsh }\end{array}$ & 6 & & & \\
\hline P9 & $\begin{array}{l}15 . \text { Woodland, } \\
\text { wood pasture }\end{array}$ & MX 67 & 40 & 15 & 13 \\
\hline \multirow[t]{3}{*}{ P10 } & $\begin{array}{l}16 . \text { Fen } \\
\text { woodland }\end{array}$ & 10 & 9.4 & 3.5 & \\
\hline & $\begin{array}{l}\text { 17. Wet meadow } \\
\text { with coppice }\end{array}$ & & & & 5 \\
\hline & Total & 100 & 100 & 100 & 100 \\
\hline
\end{tabular}

redrawn map by estimating it from the patch measurements and the number of patch. The final landscape designs inferred from the maps are presented in Table 2. Sample mosaic landscapes for each time slice are shown in Fig. 3.

\subsection{Estimating the RSAP}

In order to estimate RSAP the following steps were carried out using the HUMPOL computer model (Bunting and Middleton, 2005):

1. Landscapes of $20 \mathrm{~km} \times 20 \mathrm{~km}$ (Fig. 3) with cell size of $10 \mathrm{~m}$ were simulated using the program MOSAIC. Vegetation communities/ patches were placed randomly (see Sugita, 1994; Sugita et al., 1997, 1999) by the random scripting of the program until the desired percentage in the landscape (Table 2) was achieved. Each scenario was replicated five or six times in order to obtain a number of pollen samples/lakes that was at least double the number of taxa included in the scenario (Sugita, 2007b) (see below).
2. Taxon and community parameters were defined in POLFLOW (Tables 2 and 3). Nine lakes were placed in a $8 \mathrm{~km} \times 8 \mathrm{~km}$ square in the middle of each $20 \mathrm{~km} \times 20 \mathrm{~km}$ landscape, leaving a $6 \mathrm{~km}$ buffer zone to the edge of the scenario; in order to minimize autocorrelation, a distance of $4 \mathrm{~km}$ (i.e. twice the expected RSAP as in Hellman et al., 2009) was left between each site. Vegetation data were collated in $10 \mathrm{~m}$ wide concentric rings out to $4 \mathrm{~km}$ around each sampling point. Data for each scenario were then prepared for ERV analysis using the program POLLOG.

3. Pollen loading was simulated and ERV calculations implemented by the program polsim-v3.exe (Sugita, 2002 unpublished; see above). Pollen counts of 1000 grains were simulated using the Ring-Source model, and ERV analysis carried out using ERV-model 3 (Sugita, 1993) for lake sites and the Prentice's model (Prentice, 1985) for bogs (see Introduction section for more details on ERV-models and the RingSource model). ERV-model 3 (Sugita, 1994) is used to calculate the

\section{Table 2}

Percentage cover of matrix (MX), patches (P1-P10), and taxa in the MOSAIC-simulated landscapes of the Early Neolithic, Late Bronze Age, Viking Age, and Middle Ages Correspondence of patches P1 to P10 to the vegetation types in the original maps of the Ystad project is presented in Table 1. P1 arable, P2 dry grassland with scattered shrubs, P3 dry and mesic meadow, and open pasture, P4 pasture with scattered trees and shrubs, P5 arable land with coppice, semi open coppice pasture with meadows, and dry and mesic meadow with coppice, $\mathrm{P} 6^{*}$ open sand heath $(*$ indicates that the patch is included in each simulated landscape, even though represented only on the regional Ystad project's maps along the coast, however most probably an element of the Ystad area as a whole even inland), P7 wet grassland, wet meadow, and fen/peatland, P8 salt meadow and brackish marsh, P9 woodland and wood pasture, P10 fen woodland and wet meadow with coppice. The matrix (MX) is similar to P9 for the Early Neolithic, to P5 for the Late Bronze Age, to P2 for the Viking Age, and P3 for the Middle Ages. Al Alnus, Be Betula, Co Corylus, Fa Fagus, Fr Fraxinus, Pi Pinus, Qu Quercus, Ti Tilia, Ul Ulmus, Ca Calluna, Ce Cerealia, Cy Cyperaceae, Gr Gramineae, Pl Plantago lanceolata, Ru Rumex acetosa type, Se Secale

\begin{tabular}{|c|c|c|c|c|c|c|c|c|c|c|c|c|c|c|c|c|}
\hline Patch & $\begin{array}{l}\text { Radius } \\
\text { (m) }\end{array}$ & & $\mathrm{Al}$ & Be Co & $\mathrm{Fa}$ & $\mathrm{Fr}$ & $\mathrm{Pi}$ & $\mathrm{Qu}$ & $\mathrm{Ti} \mathrm{U}$ & $\mathrm{Ca}$ & $\mathrm{Ce}$ & Cy Gr & $\mathrm{Pl}$ & Ru S & & Total \\
\hline \multicolumn{17}{|c|}{ Köpinge area - Early Neolithic } \\
\hline P5 & 100 & 1 & & 210 & & & & 2 & 6 & & 35 & 30 & 5 & 10 & & 100 \\
\hline P6* & 500 & 1 & & & & & 15 & 15 & & 70 & & & & & & 100 \\
\hline P7 & 500 & 15 & & & & & & & & & & 5050 & & & & 100 \\
\hline P8 & 250 & 6 & & & & & & & & & & 3060 & & 10 & & 100 \\
\hline P9 & MX & 67 & & 1710 & & 10 & & 25 & 255 & & 1 & 5 & 1 & 1 & & 100 \\
\hline P10 & 500 & 10 & 70 & 20 & & 10 & & & & & & & & & & 100 \\
\hline Tot & & 100 & & & & & & & & & & & & & & \\
\hline \multicolumn{17}{|c|}{ Bjäresjö area - Late Bronze Age } \\
\hline P1 & 50 & 0.2 & & & & & & & & & 20 & 20 & & 105 & & 100 \\
\hline P5 & MX & 40 & & 610 & & & 2 & 6 & & & & 56 & 10 & 10 & & 100 \\
\hline P6* & 500 & 1 & & & & & 15 & 15 & & 70 & & & & & & 100 \\
\hline P7 & 100 & 9.4 & & & & & & & & & & 5050 & & & & 100 \\
\hline P9 & 1000 & 40 & & 1513 & 6 & 5.5 & & 20 & 205 & & 1.5 & 10 & 2 & 2 & & 100 \\
\hline P10 & 250 & 9.4 & 70 & 2010 & & & & & & & & & & & & 100 \\
\hline Tot & & 100 & & & & & & & & & & & & & & \\
\hline \multicolumn{17}{|c|}{ Bjäresjö area - Viking Age } \\
\hline P1 & 250 & 0.5 & & & & & & & & & 20 & 20 & 5 & 104 & 45 & 100 \\
\hline P2 & MX & 50 & & 1010 & & & 4 & & 1 & & & 50 & 15 & 10 & & 100 \\
\hline P5 & 1000 & 15 & & 1012 & & & 5 & 10 & & & & 53 & 5 & 5 & & 100 \\
\hline P6* & 500 & 1 & & & & & 15 & 15 & & 70 & & & & & & 100 \\
\hline P7 & 500 & 15 & & & & & & & & & & 5050 & & & & 100 \\
\hline P9 & 250 & 15 & & 1715 & 10 & 5 & & 25 & 141 & & 2 & 7 & 2 & 1 & 1 & 100 \\
\hline P10 & 500 & 3.5 & 48 & 10 & & 2 & & & & & & 2020 & & & & 100 \\
\hline Tot & & 100 & & & & & & & & & & & & & & \\
\hline \multicolumn{17}{|c|}{ Bjäresjö area - Middle Ages } \\
\hline P1 & 250 & 20 & & & & & & & & & 16 & 40 & 8 & 152 & 21 & 100 \\
\hline P2 & 250 & 8 & & 1010 & & & 4 & & 1 & & & 50 & 15 & 10 & & 100 \\
\hline P3 & MX & 22 & & & & & & & & & & 64 & 16 & 20 & & 100 \\
\hline P4 & 250 & 7 & & 78 & 2 & & & 6 & & & & 46 & 14 & 17 & & 100 \\
\hline P6* & 500 & 5 & & & & & 15 & 15 & & 70 & & & & & & 100 \\
\hline P7 & 250 & 20 & & & & & & & & & & 5050 & & & & 100 \\
\hline P9 & 500 & 13 & & 1515 & 15 & 5 & & 37 & 21 & & 1 & 5 & 1 & 2 & 1 & 100 \\
\hline P10 & 50 & 5 & 48 & 10 & & 2 & & & & & & 2020 & & & & 100 \\
\hline Total & & 100 & & & & & & & & & & & & & & \\
\hline
\end{tabular}


Table 3

Pollen productivity estimates (PPEs) and fall speed of pollen (FS) (after Broström et al., 2005) for the taxa used in the simulation runs. PPEs after Sugita et al. (1999) for all taxa except *Broström et al. (2005) and **Nielsen and Sugita (2005). PPEs after Sugita et al. (1999) are recalculated to be relative to Gramineae

\begin{tabular}{llc}
\hline Taxa & Fall speed & PPE \\
\hline Alnus & 0.021 & 4.23 \\
Betula & 0.024 & 8.94 \\
Calluna** & 0.038 & 1.10 \\
Cerealia** & 0.060 & 0.75 \\
Corylus & 0.025 & 1.42 \\
Cyperaceae* & 0.035 & 1.00 \\
Fagus & 0.057 & 6.73 \\
Fraxinus & 0.022 & 0.67 \\
Pinus & 0.031 & 5.71 \\
Plantago** & 0.029 & 0.90 \\
Gramineae* & 0.035 & 1.00 \\
Quercus & 0.035 & 7.60 \\
Rumex** & 0.018 & 1.56 \\
Secale & 0.060 & 3.04 \\
Tilia & 0.032 & 0.80 \\
Ulmus & 0.032 & 1.27 \\
\hline
\end{tabular}

RSAP by comparing simulated pollen proportions and cumulative distance-weighted vegetation data at sequential distances away from the sampling points (see Introduction section for ERV-models). It calculates the "likelihood function score" [the negative value of the Support function for the multinomial distribution function (sensu Edwards, 1972)] for the corrected pollen-vegetation relationship for all taxa over distance from the sampling point. The RSAP is defined as the distance at which the likelihood function scores reach an asymptote (Sugita, 1994). Calculation was made for three different basin sizes ( $25 \mathrm{~m}, 70 \mathrm{~m}$ and $250 \mathrm{~m}$ radius). The pollen productivity estimates (PPEs) and the values for fall speed of pollen are according to Hellman et al. (2008a, 2008b) (Table 3). Neutral atmospheric conditions (e.g. Bunting et al., 2004) and a wind speed of $3 \mathrm{~m} \mathrm{~s}^{-1}$ (e.g. Sugita et al., 1999; Broström et al., 2005) were assumed. The background pollen signal was specified in polsim-v3 using the regional vegetation abundance for the selected time windows as reconstructed from a pollen record of a large lake within the Ystad project area (Krageholmssjön, $186 \mathrm{ha}$ ) and application of the REVEALS model (Sugita, 2007a; see Introduction section) (Sugita et al., in press) (Table 4).

The radius of the RSAP was identified using the "moving-window linear regression method" (MWLR) (Sugita in Gaillard et al., 2008). This method fits a straight line to the data points (likelihood function scores) within the moving-window (300 $\mathrm{m}$ in our case) and tests whether the slope is statistically different from zero or not. The distance at and beyond which the slope becomes consistently not different from zero $(p>0.05)$ is defined as the estimate for the Relevant Source Area of Pollen. This method approximates the slope at a given distance (i.e., the middle of the moving-window) using regression, instead of estimating the slope at a point at the distance using the first derivative of the curve of the likelihood function score. Therefore, selection of the width of the moving-window will affect the RSAP estimates. Sugita (in Gaillard et al., 2008) showed that the estimates become bigger as the width of the moving-window increases. It should be stressed that running the polsim-v3.exe program several times on the same dataset will result in slightly different values of "likelihood scores" for each individual run because of the limitations in the ERV-models of estimating multiple parameters (Press et al., 1992). This effect will influence the definition of the RSAP using the MWLR method. Preliminary tests have shown that, in our case, the differences of RSAP between runs are of ca. +/-200 m.

\section{Results}

Results are presented in Figs. 4-5 and Table 5. In the following text (Discussion and Conclusions sections included), we use the following abbreviations: EN = Early Neolithic, LBA = Late Bronze Age, VA = Viking Age, $\mathrm{MA}=$ Middle Ages, $250 \mathrm{~L}=$ lake of $250 \mathrm{~m}$ radius .

The simulated RSAPs (Table 5) vary between ca. $1300 \mathrm{~m}$ and $3000 \mathrm{~m}$ for bogs and between $1200 \mathrm{~m}$ and $2600 \mathrm{~m}$ for lakes. For very small sites (25 m in radius), RSAPs range between ca. 1300 and $1900 \mathrm{~m}$ for bogs, and between ca. $1200 \mathrm{~m}$ and $1900 \mathrm{~m}$ for lakes. For larger sites (250 $\mathrm{m}$ in radius), the range is between ca. $2100 \mathrm{~m}$ and $3000 \mathrm{~m}$ for bogs and ca. $2000 \mathrm{~m}$ and $2600 \mathrm{~m}$ for lakes.

Increasing basin size broadly increases the estimated RSAP for all landscapes, although $25 \mathrm{~m}$ and $70 \mathrm{~m}$ radius sites in the VA and MA landscape scenarios have similar estimated RSAPs (Fig. 5). In all cases (except for EN250L), the estimated RSAP for bogs and lakes of the same size lie within the expected range of variation due to random factors in MOSAIC landscape replicates (Hellman et al., 2009). For a given basin size, the estimated RSAP is highest in the EN landscape (except for EN250L), has similar intermediate values in the LBA and VA landscapes, and is lowest in the MA landscape. However, when the range of possible variation is considered, only EN and MA values are distinctly different (their estimated range of variation does not overlap). The largest range of estimated RSAPs is seen for $70 \mathrm{~m}$ radius lakes.

\section{Discussion}

The forward modelling approach is an alternative (and a complement) to the backward modelling approach of Sugita (2007b) to estimate RSAP in the past. It provides an independent estimate of RSAP that can be compared to the one obtained using the method of Sugita (2007b). Moreover, it allows testing the effect of different reconstructions of the past landscape in terms of spatial distribution and size of patches. Given that detailed reconstructions of past vegetation and landscape are available, these hypothetical landscapes of the past can be used as a basis for credible simulated landscapes. Such an approach might be accused of reasoning in a circle, as the past RSAP is a prerequisite for quantitative reconstruction of past vegetation within the area defined as the RSAP. However, in the case of this study, most of the original landscape reconstructions (maps)

Table 4

REVEALS-inferred percentages of regional vegetation abundance in Skåne used for the RSAP calculation applying ERV-model 3 (Sugita, 1993). The age of the selected archaeological periods and the pollen assemblages used in the REVEALS reconstruction for each time slice are also indicated. The pollen data is from Lake Krageholmssjön (Gaillard, 1984). The REVEALS reconstruction was performed by Sugita et al. (in press) using the sum of the pollen counts within consecutive time windows of $250 \mathrm{yr}$ through the entire Holocene. The values in the table are the means of the REVEALS percentage values included in each selected period

\begin{tabular}{lllll}
\hline Period & EN & LBA & VA & MA \\
\hline Age (cal yr BC/AD) & $4000-3300$ BC & $1000-500$ BC & AD 800-1050 & AD 1050-1500 \\
Age (cal yr BP) & $5950-5250 B P$ & $2950-2450$ BP & $1150-900$ BP & $900-450$ BP \\
Time slice in pollen & $6100-5300$ BP & $2733-2413$ BP & $1213-928$ BP & $898-498$ BP \\
record & & & & \\
Taxa & & & & \\
Alnus & 11.7 & 4.5 & 5.3 & 3.3 \\
Betula & 1.9 & 2.0 & 2.1 & 1.8 \\
Corylus & 35.0 & 16.0 & 10.2 & 9.1 \\
Fagus & 0 & 1.0 & 17.0 & 13.4 \\
Fraxinus & 10.6 & 2.8 & 1.8 & 0.5 \\
Pinus & 3.3 & 3.6 & 2.0 & 3.0 \\
Quercus & 5.0 & 2.1 & 3.0 & 2.4 \\
Tilia & 12.5 & 1.8 & 1.8 & 1.3 \\
Ulmus & 7.5 & 1.4 & 1.1 & 0.9 \\
Calluna & 0 & 0.3 & 0.1 & 0.4 \\
Cerealia & 0 & 8.7 & 14.4 & 22.0 \\
Cyperaceae & 3.1 & 9.2 & 5.6 & 7.0 \\
Gramineae & 9.3 & 45.3 & 32.3 & 31.0 \\
Plantago & 0.01 & 0.3 & 0.3 & 0.2 \\
Rumex & 0.3 & 0.8 & 0.6 & 1.0 \\
Secale & 0 & 0.1 & 2.2 & 2.6 \\
\hline
\end{tabular}


used are based on independent data such as settlement patterns (derived from archival and archaeological sources), maps of Quaternary geology, 19th century hydrology, and palaeohydrological data. Moreover, the landscape designs used for simulation are a simplification of the original maps, and several landscape characteristics are varied. Therefore, the approach has the advantage to capture the possible variation in RSAP for landscapes that are not entirely hypothetical or theoretical (as in e.g. Hellman et al., 2009), but are based on plausible characteristics of the past, and the causes behind variation in RSAP can be better understood. The latter contrasts with the backward modelling approach that uses empirical fossil pollen records. In that case, causes behind variation in RSAP cannot be identified.

Sugita et al. (1999) proposed that differences in the distribution of the vegetation patches in the landscapes explained that the RSAP estimate was larger in the modern landscape of southern Sweden than in the forested landscapes of northern Michigan (Sugita, 1994; 1998; Calcote, 1995). The simulated landscapes of southern Sweden in Sugita et al. (1999) include more patch types that are infrequent (i.e. the mean distances between patches are longer) than the simulated landscapes in northern America. Irrespective of where the sedimentary basin is located in the landscape, the chance of having a particular vegetation patch nearby that basin in southern Sweden is smaller than it is in northern Michigan. Therefore, the predicted area (i.e. the RSAP) required to achieve constant background pollen, a criterion for the RSAP, becomes larger in southern Sweden than in northern Michigan (Sugita et al., 1999). However, Bunting et al. (2004) showed by simulation that infrequent taxa did not necessarily imply higher RSAP. Based on the results of simulation experiments, Nielsen and Sugita (2005) suggested that differences in patch size might be the main cause behind the observed differences in empirically estimated RSAP between eastern and western Denmark. Hellman et al. (2009) further explored the effect of patch size and cover on RSAP, as well as changes in spatial landscape/vegetation evenness. In that study, landscape/ vegetation evenness is defined as follows: the vegetation/landscape is perfectly even when the distribution of patches is such that the distance between all patches is equal in all directions, and all patches are of an equal size. In the real world, or in randomized landscapes as those used in the present study, vegetation or landscapes are never completely even, however the distance between patches, and patch size can be more or less equal, i.e. the more equal they are, the more even the vegetation/landscape is. The simulation results of Hellman et al. (2009) indicate that, in the case of these particular hypothetical landscapes, the major influencing factor is indeed landscape structure (in terms of patch size), as suggested earlier (Bunting et al., 2004; Broström et al., 2005), but more importantly the spatial distribution of the taxa/patches is decisive (as suggested by Sugita et al., 1999). An increase in patch size or an increase in the number of infrequent taxa/ patches in the landscape can lead to an increase in RSAP, but only if these changes imply at the same time differences in spatial patch/taxa distribution over the landscape from more or less even to very uneven (even being defined as above) (Hellman et al., 2009).

Variation in estimated RSAP between time slices was expected to occur as a response to changes in the spatial properties of the vegetation mosaic, especially in terms of patch size and vegetation/ landscape evenness (see definition above). Because the landscape designs include significantly larger patches in LBA and VA landscapes than in EN or MA landscapes (Fig. 3), one would predict smaller RSAP for MA and EN landscapes than for VA and LBA landscapes. The estimated RSAP values for MA landscapes fit this model, but the EN landscape has the largest estimated RSAPs. This might be due to the fact that small patches are relatively infrequent in the EN landscape, resulting in large areas of matrix that form large patches, which leads to a lower vegetation/landscape evenness, and therefore to a higher estimated RSAP.

During the EN, land-use was extensive but influenced the spatial structure of the landscape at a small local scale, i.e. the landscape was characterised by large patches of "untouched areas", and a few small patches of human-induced vegetation (e.g. Berglund et al., 1991). These landscape characteristics are apparent in the landscape design of the EN period (Fig. 3A). Such a landscape structure will result in relatively large RSAP according to our suggested explanation above (Hellman et al., 2009). During LBA and VA, land-use is assumed to have spread over most of the landscape and, at the same time, the landscape structure was influenced by the development of permanent settlements (e.g. Berglund, 1991). It led to a larger variety of vegetation patches distributed over the entire landscape. This trend probably amplified during the MA with an increase in land-use diversity and, therefore, an even larger variety of vegetation patches of smaller size than earlier. According to the hypothesis presented by Hellman et al. (2009) on the effect of spatial vegetation/landscape evenness on RSAP, the assumed consequence of the land-use history of southern Sweden as reconstructed in Berglund (1991) would imply smaller RSAP during LBA and VA than during EN, and smaller RSAP during MA than during LBA and VA, because spatial vegetation/landscape evenness increased gradually from EN until MA. This "land-use explanation" for changes in RSAP is, however, hypothetical and should be further tested.

The simulated RSAPs for lakes and bogs of various sizes (Table 5) are in a similar order of magnitude as earlier estimates of RSAPs obtained from hypothetical or empirical data in southern Scandinavia (Sugita et al., 1999; Broström et al., 2005; Nielsen and Sugita, 2005). RSAP values within this range have been calculated for present-day cultural landscapes in southern Sweden (ca. $1000 \mathrm{~m}$ for lakes of $100 \mathrm{~m}$ radius; Sugita et al., 1999), and for AD 1800 landscapes in Denmark (1700 m for lakes of 100-500 m radius; Nielsen and Sugita, 2005). Similarly, simulation tests using lakes of $50 \mathrm{~m}$ in radius in simple, hypothetical tree or herb/tree landscapes with Scandinavian taxa characteristic of the Holocene period resulted in RSAP estimates within the range of ca. $1000 \mathrm{~m}$ to $2500 \mathrm{~m}$ whatever the scenario (Hellman et al., 2009). It is also interesting to note that differences in RSAPs between lakes and bogs are very small and not consequent, i.e. RSAPs for bogs are either larger or smaller than RSAPs for lakes. Moreover, the differences are within the range of the error estimate of $\pm 200 \mathrm{~m}$ (see Methods section above). The pollen dispersal model of Sugita for lakes (Sugita, 1993) predicts that the characteristic radius for individual pollen types is significantly smaller for lakes than for bogs. The fact that the estimated RSAP do not show this type of difference between lakes and bogs in our study also supports the idea that spatial distribution of patches plays a more important role for the RSAP than pollen dispersal-deposition properties alone.

Based on the present study, we assume that small sites will seldom have RSAPs smaller than $1000 \mathrm{~m}$ or larger than $2500 \mathrm{~m}$ in past cultural landscapes of southern Scandinavia. This would be the kind of RSAP range that could be used for reconstruction of local vegetation abundance applying the Landscape Reconstruction Algorithm in this region (Sugita 2007a, 2007b). However, real landscapes are not random and will often be more heterogeneous in terms of spatial distribution of patches and taxa. Therefore, past RSAPs might be slightly larger than the RSAPs estimated in this and earlier studies using hypothetical randomized landscapes. Comparison with RSAP

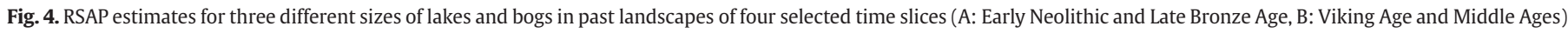

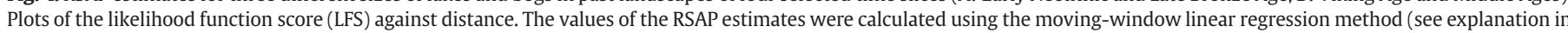
the text), and are shown with an arrow in each plot. The results are summarized in Table 5. 
A

Bog

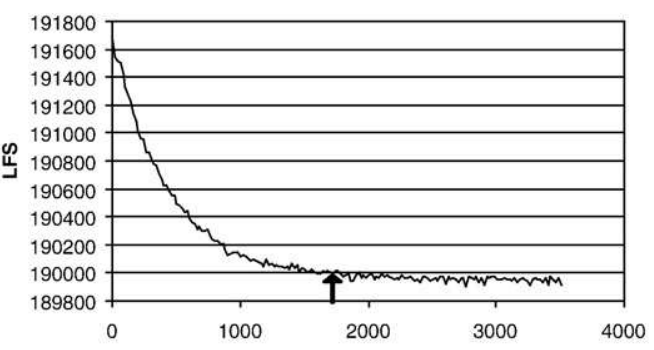

EN 25m

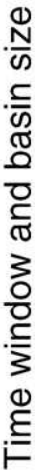

LBA $25 \mathrm{~m}$
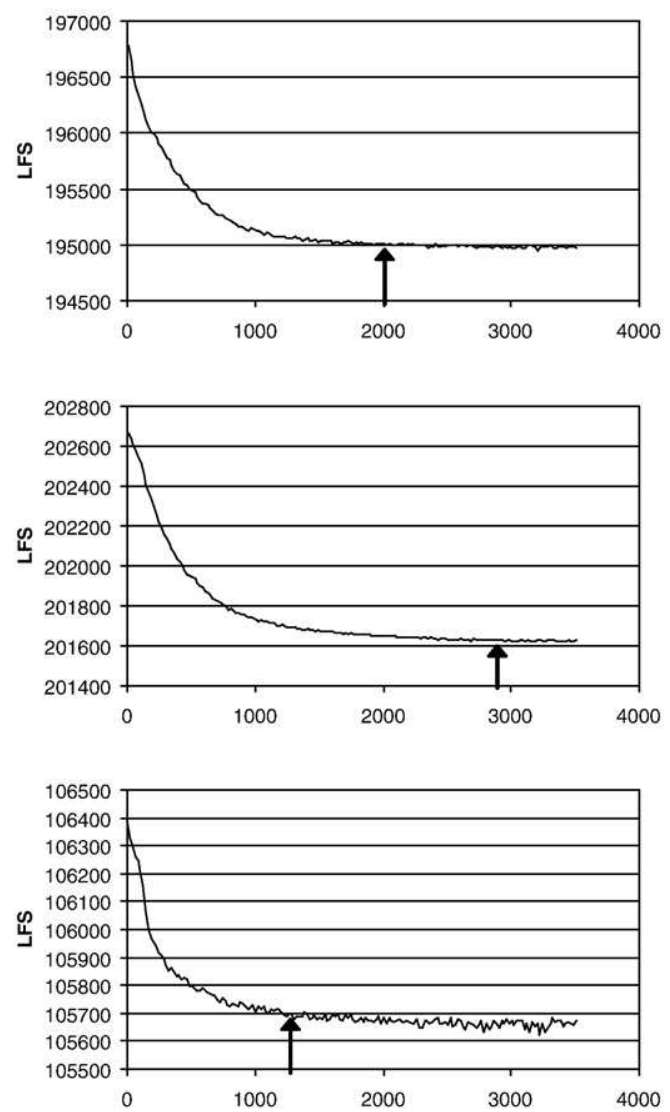

LBA $70 m$

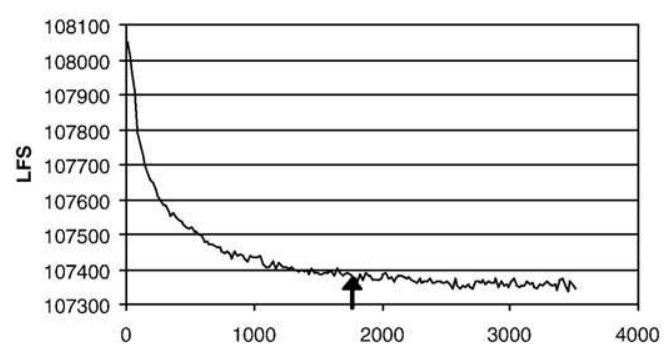

LBA $250 \mathrm{~m}$

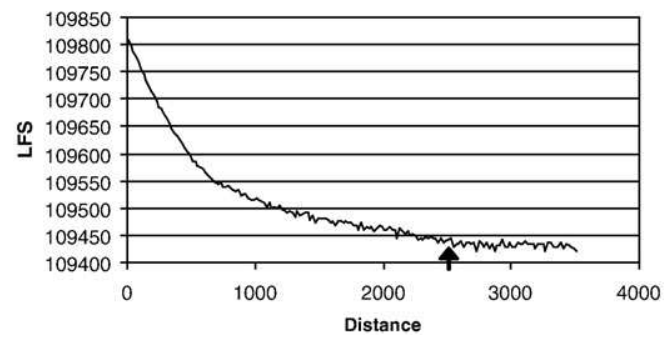

Lake
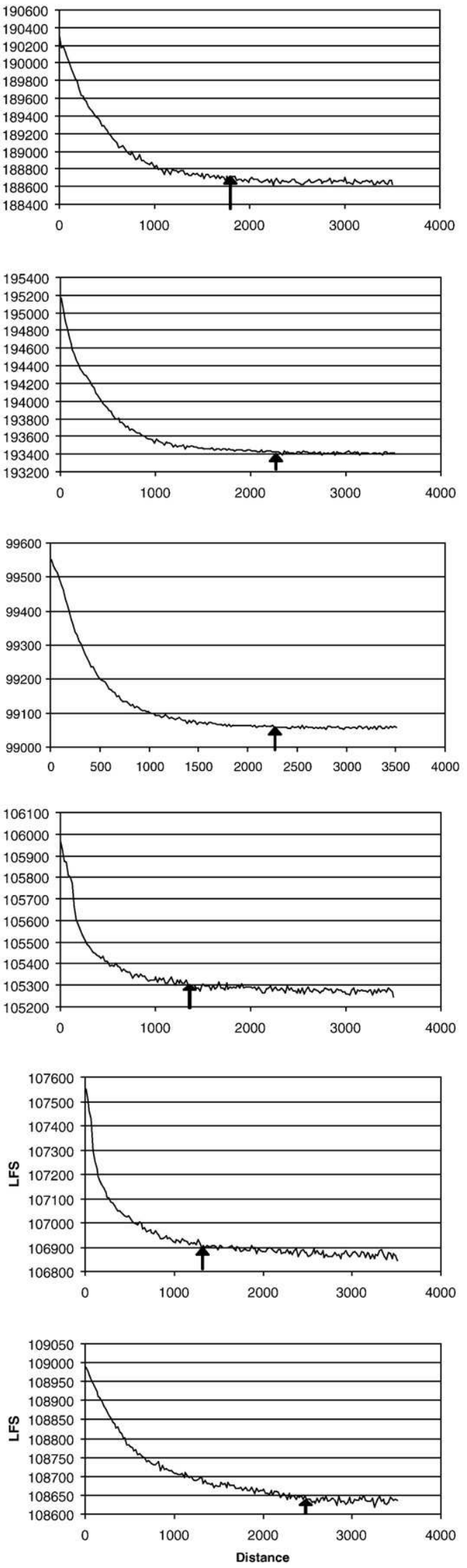
B

VA $25 \mathrm{~m}$

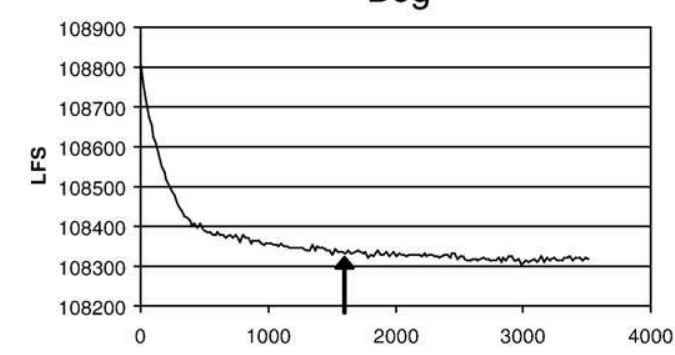

VA $70 \mathrm{~m}$
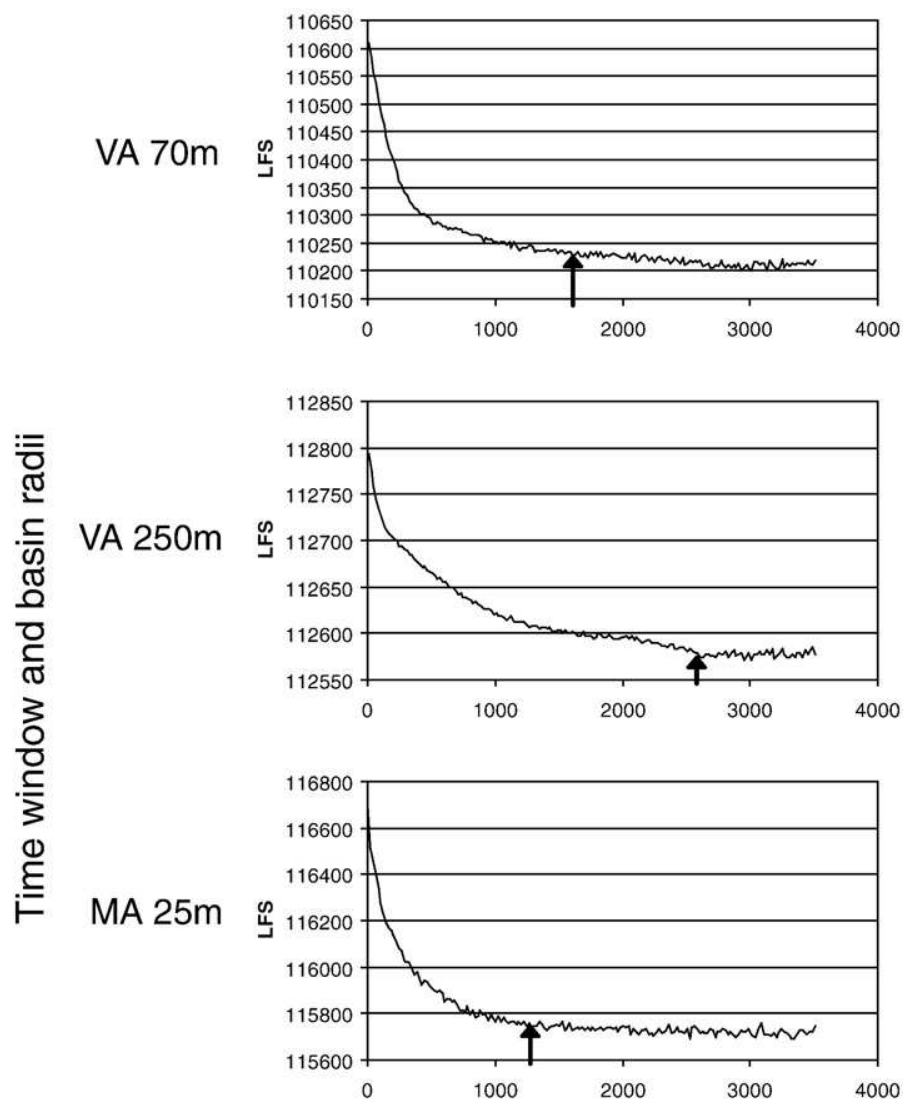

MA $70 m$
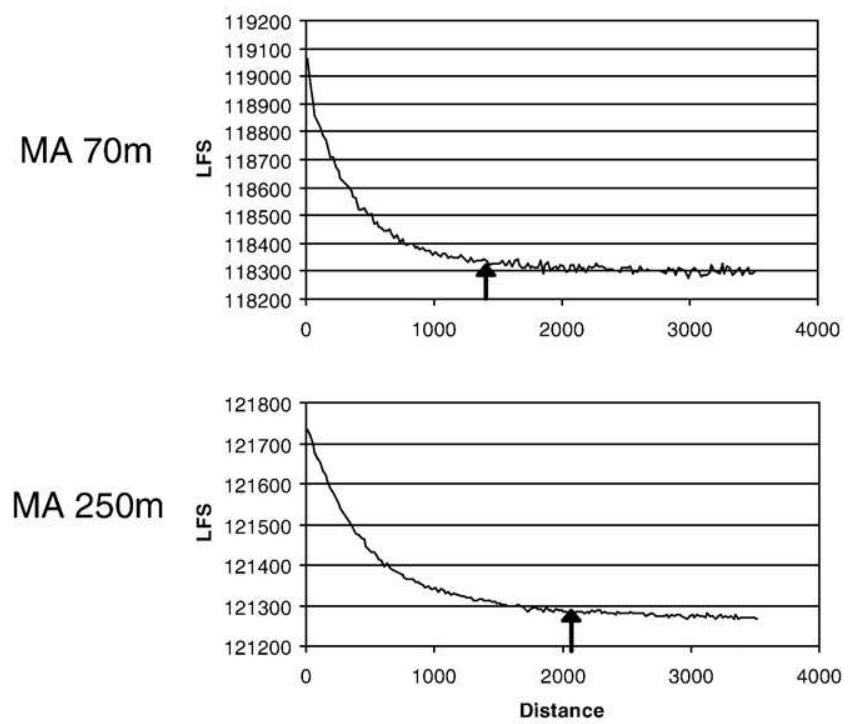

Fig. 4 (continued).

\section{Lake}
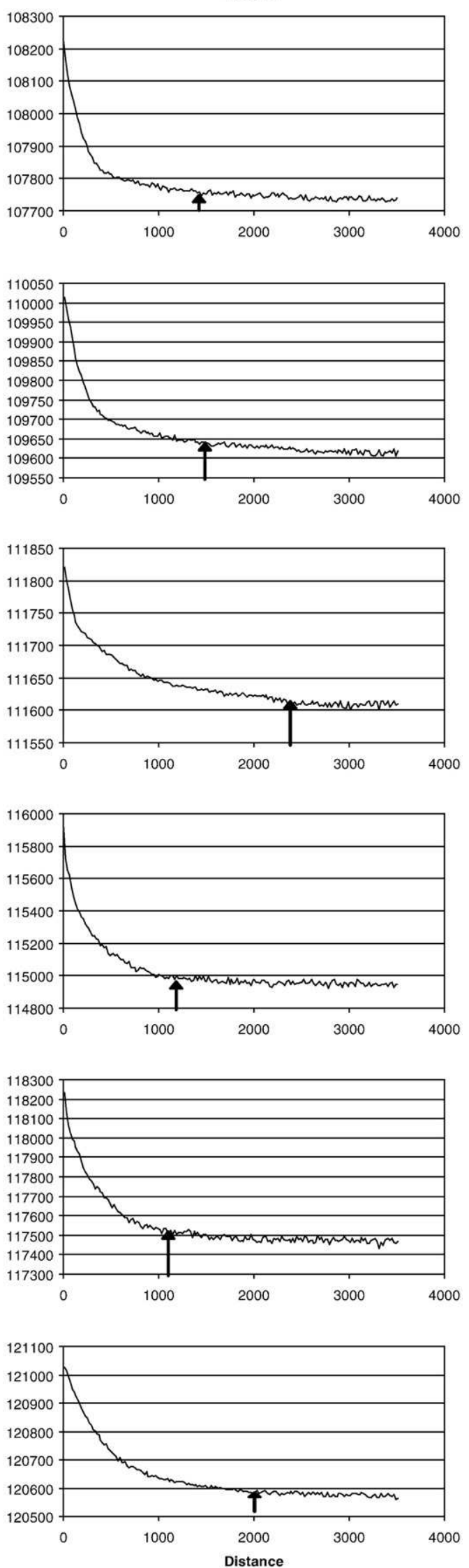

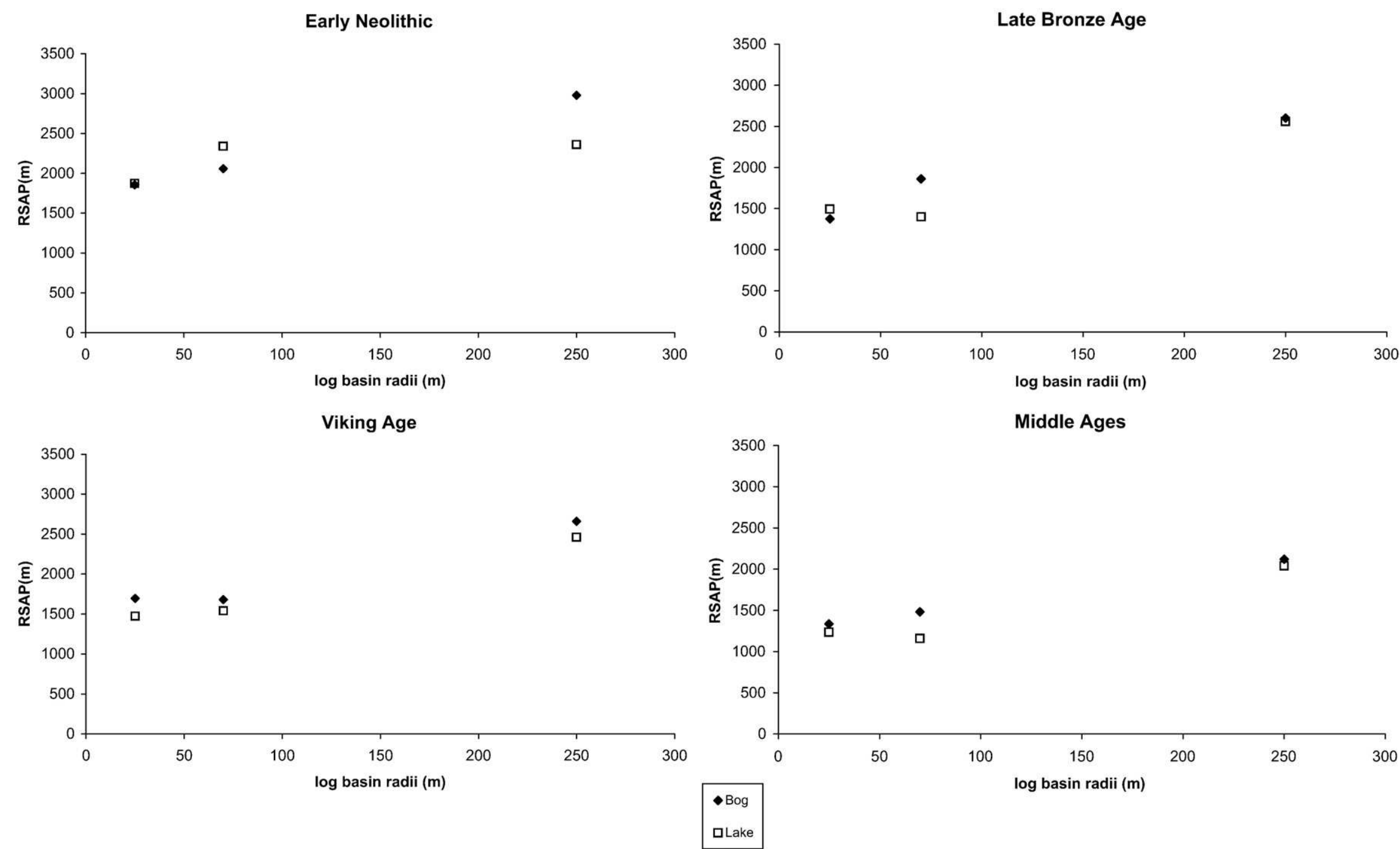

Fig. 5. RSAPs plotted against lake (empty square) and bog (filled diamond) radius (in m) for four selected time windows, i.e. Early Neolithic, Late Bronze Age, Viking Age and Middle Ages. 
Table 5

RSAPs for four time windows (see Fig. 4A-B for plots of likelihood scores). Abbreviations: $\mathrm{EN}=$ Early Neolithic, $\mathrm{LBA}=$ Late Bronze Age, $\mathrm{VA}=$ Viking Age, $\mathrm{MA}=$ Middle Ages

\begin{tabular}{llllllll}
\hline Time window & \multicolumn{3}{l}{ Bog radii } & & & \multicolumn{2}{l}{ Lake radii } \\
\cline { 2 - 3 } \cline { 7 - 8 } & $25 \mathrm{~m}$ & $70 \mathrm{~m}$ & $250 \mathrm{~m}$ & & $25 \mathrm{~m}$ & $70 \mathrm{~m}$ & $250 \mathrm{~m}$ \\
\hline EN & 1855 & 2060 & 2980 & & 1875 & 2340 & 2360 \\
LBA & 1375 & 1860 & 2600 & & 1495 & 1400 & 2560 \\
VA & 1695 & 1680 & 2660 & & 1475 & 1540 & 2460 \\
MA & 1335 & 1480 & 2120 & & 1235 & 1160 & 2040 \\
\hline
\end{tabular}

values predicted using the backward modelling approach (Sugita, 2007b; Gaillard et al., in preparation) will allow us to confirm or improve our knowledge on the range of RSAP estimates in the past for southern Sweden. Predicted RSAPs calculated from modern pollenvegetation data (Gaillard et al., 1998; Broström et al., 1998) using the backward modelling approach are of $2000 \mathrm{~m}$ in Småland (lake sizes 0.1-8 ha; mainly 1-2 ha) and $5000 \mathrm{~m}$ in Skåne (lake sizes 1-20 ha, mostly 1-4 ha) (Sugita, unpublished, personal communication). However, these results are still preliminary, and it is too early to compare them with the results presented here. Nevertheless, a very large RSAP for the modern cultural landscape of Skåne is a reasonable estimation. Today's landscape is very different from that of the beginning of the 20th century (Berglund et al., 1991). It is less patchy, and the distribution of trees in the landscape is very uneven (see definition above). According to our assumption, such a very uneven landscape would imply large RSAPs. The early 20th century landscape of Skåne was comparable to the AD 1800 landscape of Denmark for which RSAP values of ca. $1700 \mathrm{~m}$ for $100-500 \mathrm{~m}$ radius lakes were estimated (Nielsen and Sugita, 2005), which falls within the range of values we have obtained in this study.

\section{Conclusions}

RSAP estimates for hypothetical past landscapes in southern Sweden (province of Skåne) vary between the selected time periods even when the size and type of basin is kept constant.

The most probable explanation for these differences in RSAP is assumed to be changes in patch size and spatial distribution of patches. Based on our study, and given the type of setting in southern Scandinavia in terms of taxa composition and traditional land-use, we assume that the RSAP for small-size lakes (25-250 m radius) will most likely range between $1000 \mathrm{~m}$ and $2000 \mathrm{~m}$ for lakes of $\leq 70 \mathrm{~m}$ radius. If the Landscape Reconstruction Algorithm is used for reconstruction of past vegetation at the local spatial scale, the forward modelling approach is very useful to assess the possible effects on RSAP of changes in vegetation/landscape characteristics between different periods of the past. Moreover, comparison of RSAP estimates obtained using both the forward and backward modelling approaches will be very important to identify the most credible RSAPs in the past.

\section{Acknowledgements}

We gratefully acknowledge the financial support from the Swedish Research Foundation (VR) and from the Nordic Research Council (NordForsk). This paper is a contribution to the POLLANDCAL (POLlenLANDscape CALibration) network sponsored by NordForsk (network website: www.geog.ucl.ac.uk/ecrc/pollandcal). We are indebted to all POLLANDCAL members for useful and inspiring discussions during the numerous workshops held between 2002 and 2005. We want to thank especially Richard Middleton for discussions and modifications to the HUMPOL computer programs over the years, and Shinya Sugita for his ever-lasting patience and help with theoretical aspects of the models and computer programs. Finally, we are very grateful to two reviewers for their comments, corrections, and suggestions to improvements.

\section{References}

Andersen, S.T., 1970. The relative pollen productivity and representation of north European trees, and correction factors for pollen spectra. Danm. Geol. Unders. II, vol. 96, 1-99.

Andersen, S.T., 1973. The differential pollen productivity of trees and its significance for the interpretation of pollen diagram from a forested region. In: Birks, H.J.B., West, R.G. (Eds.), Quaternary Plant Ecology, pp. 109-116. Blackwell.

Berglund, B.E., 1973. Pollen dispersal and deposition in an area of south eastern Sweden some preliminary results. In: Birks, H.J.B., West, R.G. (Eds.), Quaternary Plant Ecology, pp. 117-119. Blackwell.

Berglund, B.E. (Ed.), 1991. The Cultural Landscape During 6000 years in Southern Sweden - the Ystad Project. Ecol. Bull., vol. 41. 495 pp.

Berglund, B.E., Malmer, N., Persson, T., 1991. Landscape-ecological aspects of long-term changes in the Ystad area. 1991 In: Berglund, B.E. (Ed.), The Cultural Landscape During 6000 years in Southern Sweden - the Ystad Project. Ecol. Bull., vol. 41, pp. 405-424.

Birks, H.J.B., Birks, H.H. (Eds.), 1980. Quaternary Palaeoecology. Edward Arnold, London Bradshaw, R.H.W., Webb III, T., 1985. Relationship between contemporary pollen and vegetation data from Wisconsin and Michigan, USA. Ecology 66 (3), 721-737.

Broström, A., Gaillard, M.J., Ihse, M., Odgaard, V.B., 1998. Pollen-landscape relationships in modern analogues of ancient cultural landscapes in southern Sweden - a first step towards quantification of vegetation openness in the past. Veg. Hist. Archaeobot. 7, 189-201.

Broström, A., Sugita, S., Gaillard, M.-J., 2004. Pollen productivity estimates for the reconstruction of past vegetation cover in the cultural landscape of southern Sweden. Holocene 14 (3), 368-381.

Broström, A., Sugita, S., Gaillard, M.J., Pilesjö, P., 2005. Estimating the spatial scale of pollen dispersal in the cultural landscape of southern Sweden. Holocene 15 (2) 252-262.

Bunting, J., Middleton, R., 2005. Modelling pollen dispersal and deposition using HUMPOL software, including simulating windroses and irregular lakes. Rev. Palaeobot. Palynol. 134 (3-4), 185-196.

Bunting, J., Gaillard, M.J., Sugita, S., Middleton, R., Broström, A., 2004. Vegetation structure and pollen source area. Holocene 14 (5), 651-660.

Calcote, R.R., 1995. Pollen source area and pollen productivity: evidence from forest hollows. J. Ecol. 83, 591-602.

Davis, M.B., 1963. On the theory of pollen analysis. Am. J. Sci. 261, 897-912.

Davis, M.B., 2000. Palynology after Y2K - understanding the source area of pollen in sediments. Ann. Rev. Earth Plan. Sci. 28, 1-18.

Davis, M.B., Moeller, R.E., Ford, J., 1984. Sediment focusing and pollen influx. In: Haworth, Y., Lund, J.W.G. (Eds.), Lake sediments and environmental history. University of Leicester Press, Leicester, pp. 261-293.

Edwards, A.W.F., 1972. Likelihood: an account of the statistical concept of likelihood and its application to scientific inference. Cambridge University Press, London.

Gaillard, M.J., 1984. A palaeohydrological study of Krageholmssjön (Scania, South Sweden) - regional vegetation history and water-level changes. LUNDQUA Report 2540 pp.

Gaillard, M.J., Birks, H.J.B., Ihse, M., Runborg, S., 1998. Pollen/landscape calibrations based on modern pollen assemblages from surface-sediment samples and landscape mapping - a pilot study in South Sweden. In: Gaillard, M.-J., Berglund, B.E., Frenzel, B., Huckriede, U. (Eds.), Quantification of Land Surfaces Cleared of Forests During the Holocene. Palaeoklimaforschung/Palaeoclimate Research, vol. 27. Gustav Fisher Verlag, Stuttgart, pp. 31-52.

Gaillard, M.J., Sugita, S., Bunting, M.J., Middleton, R., Broström, A., Caseldine, C., Giesecke, T., Hellman, E.V., Hicks, S., Hjelle, K., Langdon, C., Nielsen, A.-B., Poska, A., von Stedingk, H., Veski, S., POLLANDCAL members, 2008. The use of modelling and simulation approach in reconstructing past landscapes from fossil pollen data: a review and results from the POLLANDCAL network. Veg. Hist. Archaeobot. 17 (5), 419-444. doi:10.1007/s00334-008-0169-3.

Gaillard, M.-J., Sugita, S., Börkman, L., Greisman, A., Linbladh, M., in preparation. Application of LOVE for quantitative vegetation reconstructions at the small spatial scale in southern Sweden. Holocene.

Hellman, S., Gaillard, M.J., Bunting, M.J., 2009. Relevant source area of pollen in patchy cultural landscapes and signals of anthropogenic landscape disturbance in the pollen record: a simulation approach. Rev. Palaeobot. Palynol. 153, 245-258.

Hellman, S., Gaillard, M.J., Broström, A., Sugita, S., 2008a. The REVEALS model, a new tool to estimate past regional plant abundance from data in large lakes: validation in southern Sweden. J. Quat. Sc. 23 (1), 21-42.

Hellman, S., Broström, A., Gaillard, M.J., Sugita, S., 2008b. Effects of the sampling design and selection of parameter values on pollen-based quantitative reconstructions of regional vegetation: a case study in southern Sweden using the REVEALS model. Veg. Hist. Archaeobot. 17 (5), 445-460. doi:10.1007/s00334-008-0149-7.

Jackson, S.T., Kearsley, J.B., 1998. Quantitative representation of local forest composition in forest-floor pollen assemblages. J. Ecol. 86, 474-490.

Jacobson, G.L., Bradshaw, R.H.W., 1981. The selection of sites for paleovegetational studies. Quat. Res. 16, 80-96.

Janssen, C.R., 1973. Local and regional pollen deposition. In: Birks, H.J.B., West, R.G. (Eds.), Quat. Plant Ecol. pp. 31-42.

Kabeiliene, M., 1969. On formation of pollen spectra and restoration of vegetation. Transactions 11. Ministry of Geology of the USSR, Institute of Geology (Vilnius) Vilnius. (in Russian with English summary).

Mazier, F., Brostöm, A., Gaillard, M.-J., Sugita, S., Vittoz, P., Buttler, A., 2008. Pollen productivity estimates and Relevant Source Area for major taxa in a pasture woodland (Jura mountains, Switzerland). Veget. Hist. Archaeol. 17 (5), 479-496. doi:10.1007/s00334-008-0143-0. 
Middleton, R., Bunting, M.J., 2004. Mosaic v1.1: landscape scenario creation software for simulation of pollen dispersal and deposition. Rev. Palaeobot. Palynol. 132 (1-2), 61-66.

Nielsen, A.B., 2004. Modelling pollen sedimentation in Danish lakes at C. AD 1800: an attempt to validate the POLLSCAPE model. J. Biogeogr. 31, 1693-1709.

Nielsen, A.B., Sugita, S., 2005. Estimating relevant source area of pollen for small Danish lakes around AD 1800. Holocene 15 (7), 1006-1020.

Parsons, R.W., Prentice, I.C., 1981. Statistical approaches to R-values and the pollenvegetation relationship. Rev. Palaeobot. Palynol. 32, 127-152.

Prentice, I.C., 1985. Pollen representation, source area, and basin size: toward a unified theory of pollen analysis. Quat. Res. 23 (1), 76-86.

Prentice, I.C., 1988. Records of vegetation in time and space: the principles of pollen analysis. In: Huntley, B., Webb, T. (Eds.), Vegetation History. Handbook of Vegetation Science. Kluwer, Dordrecht, pp. 17-42.

Prentice, I.C., Parsons, R.W., 1983. Maximum likelihood linear calibration of pollen spectra in terms of forest composition. Biometrics 39, 1051-1057.

Press, W.H., Teukolsky, S.A., Vetterling, W.T., Flannery, B.P., 1992. Numerical Recipes in C: the Art of Scientific Computing. Cambridge University Press, Cambridge.

Soepboer, W., Vervoort, J.M., Sugita, S., Lotter, A.F., 2007. Evaluating Swiss pollen productivity estimates using a simulation approach. Veget. Hist. Archaeobot. 17 (5), 497-506. doi:10.1007/s00334-007-0128-4.

Sugita, S., 1993. A model of pollen source area for an entire lake surface. Quat. Res. 39, 239-244.

Sugita, S., 1994. Pollen representation of vegetation in quaternary sediments: theory and method in patchy vegetation. J. Ecol. 82, 881-897.

Sugita, S., 1998. Modelling pollen representation of vegetation. In: Gaillard, M.-J. Berglund, B.E., Frenzel, B., Huckriede, U. (Eds.), Quantification of Land Surfaces
Cleared of Forests During the Holocene. Palaeoklimaforschung/Palaeoclimate Research, vol. 27. Gustav Fisher Verlag, Stuttgart, pp. 125-132.

Sugita, S., 2007a. Theory of quantitative reconstruction of vegetation. I. Pollen from large sites REVEALS regional vegetation. Holocene 17 (2), 229-241.

Sugita, S., 2007b. Theory of quantitative reconstruction of vegetation. II. All you need is LOVE. Holocene 17 (2), 243-257.

Sugita, S., 2008. Effects of the atmospheric conditions on distance weighting and on the RSAP In: Gaillard, M.J. Sugita, S., Bunting, M.J., Middleton, R., Broström, A Caseldine, C., Giesecke, T., Hellman, E.V., Hicks, S., Hjelle, K., Langdon, C., Nielsen, A.-B., Poska, A., von Stedingk, H., Veski, S., POLLANDCAL members (Eds.), The use of modelling and simulation approach in reconstructing past landscapes from fossil pollen data: a review and results from the POLLANDCAL network. Veg. Hist. Archaeobot. 17 (5), 419-444. doi:10.1007/s00334-008-0169-3.

Sugita, S., MacDonald, G.M., Larsen, C.P.S., 1997. Reconstruction of fire disturbance and forest succession from fossil pollen in lake sediments: potential and limitations. In: Clark, J.S., Cashier, H., Goldammer, J.G., Stocks, B.J. (Eds.), Sediment Records of Biomass Burning and Global Change. Springer-Verlag, Berlin, pp. 387-412.

Sugita, S., Gaillard, M.J., Broström, A., 1999. Landscape openness and pollen records: a simulation approach. Holocene 9, 409-421.

Sugita, S., Gaillard, M.J., Hellman, S., Broström, A., (in press). Model-based reconstruction of vegetation and landscape using fossil pollen. Proceedings of the 35th CAA (Computer Applications and Quantitative Methods in Archaeology) Conference, Berlin, April 2007.

Tauber, H., 1965. Differential pollen deposition and the interpretation of pollen diagrams. Danm. Geol. Unders., København, II 89, 1-69. 